\title{
Exceedingly Fast Oxygen Atom Transfer to Olefins via a Catalytically Competent Nonheme Iron Species
}

\author{
Joan Serrano-Plana ${ }^{+}$Almudena Aguinaco ${ }^{+}$,Raquel Belda, Enrique García-España, \\ Manuel G. Basallote,* Anna Company, * and Miquel Costas*
}

\begin{abstract}
The reaction of $\left[\mathrm{Fe}\left(\mathrm{CF}_{3} \mathrm{SO}_{3}\right)_{2}\left(\mathrm{PyNM} \mathrm{e}_{3}\right)\right]$ with excess peracetic acid at $-40^{\circ} \mathrm{C}$ leads to the accumulation of a metastable compound that exists as a pair of electromeric species, $\left[\mathrm{Fe}^{I I I}(\mathrm{OOAc})\left(\mathrm{PyNMe}_{3}\right)\right]^{2+}$ and $\left[\mathrm{Fe}^{\mathrm{V}}(\mathrm{O})(\mathrm{OAc})\left(\mathrm{PyNM} \mathrm{N}_{3}\right)\right]^{2+}$, in fast equilibrium. Stopped-flow UV/Vis analysis confirmed that oxygen atom transfer (OAT) from these electromeric species to olefinic substrates is exceedingly fast, forming epoxides with stereoretention. The impact of the electronic and steric properties of the substrate on the reaction rate could be elucidated, and the relative reactivities determined for the catalytic oxidations could be reproduced by kinetic studies. The observed fast reaction rates and high selectivities demonstrate that this metastable compound is a truly competent OAT intermediate of relevance for nonheme iron catalyzed epoxidations.
\end{abstract}

$T_{\text {he epoxidation of olefins is a valuable reaction in organic }}$ synthesis, ${ }^{[1,2]}$ and catalytic variants relying on base metals and peroxides have recently received increasing attention because of cost and sustainability considerations. Among them, a biologically inspired approach entails the iron-catalyzed activation of hydrogen peroxide. Selected iron complexes with strong-field $\mathrm{N}_{4}$ donor ligands have been described as particularly efficient and selective homogeneous catalysts for epoxidation, providing good product yields in short reaction times under very mild reaction conditions (Scheme $1 \mathrm{a}) .{ }^{[3-7]}$ Some of these complexes are also highly stereoselective catalysts, which renders them powerful tools in fine chemistry.

[*] J. Serrano-Plana, ${ }^{[+]}$Dr. A. Company, Dr. M. Costas

Grup de Química Bioinorgànica

Supramolecular i Catàlisi (QBIS-CAT)

Institut de Química Computacional I Catàlisi (IQCC)

Departament de Química, Universitat de Girona

Campus Montilivi, 17071 Girona (Catalonia, Spain)

E-mail: anna.company@udg.edu miquel.costas@udg.edu

Dr. A. Aguinaco, ${ }^{[+]}$Dr. M. G. Basallote

Universidad de Cádiz, Facultad de Ciencias

Departamento de Ciencia de los Materiales e Ingeniería Metalúrgica y Química Inorgánica

Apdo. 40, 11510 Puerto Real, Cádiz (Spain)

E-mail: manuel.basallote@uca.es

Dr. R. Belda, Dr. E. García-España

Instituto de Ciencia Molecular (ICMol)

Universidad de Valencia

C/Catedrático José Beltrán, Paterna, Valencia 246980 (Spain)

$\left.{ }^{+}\right]$These authors contributed equally to this work.

(2) Supporting information and the ORCID identification number(s) for the author(s) of this article can be found under http://dx.doi.org/10. 1002/anie.201601396.

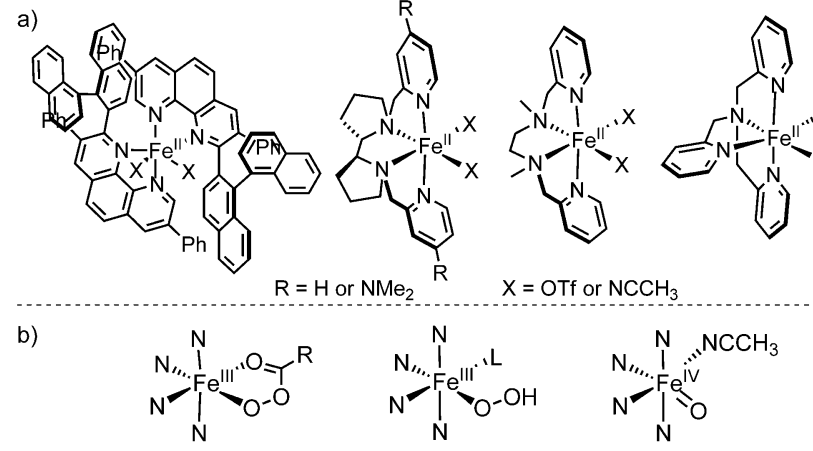

Scheme 1. a) Representative iron epoxidation catalysts. b) Metastable reaction intermediates spectroscopically characterized after the reaction of iron complexes with $\mathrm{H}_{2} \mathrm{O}_{2} / \mathrm{AcOH}$ or peracids.

A key aspect for the development of these systems as catalysts for practical organic synthesis was the discovery that the combination of hydrogen peroxide with acetic acid substantially improved their efficiency. ${ }^{[7]}$ Alternatively, excellent activities and selectivities could be attained by the use of peracetic acid and other peracids. ${ }^{[4-9]}$

The elucidation of the mechanistic details of these reactions is challenging because the active species operating in this class of highly reactive systems most often do not accumulate in solution. Furthermore, the few iron species that have been spectroscopically trapped and characterized under cryogenic conditions related to catalysis (Scheme $1 \mathrm{~b}$ ) either do not exhibit kinetic competence consistent with catalysis, ${ }^{[6,10]}$ or their kinetic competence has not been proven presumably because they are formed in very small amounts (ca. 1\%). ${ }^{[1]}$ Therefore, reaction mechanisms have been mainly interrogated by product analysis, isotopic labelling, and computational methods. Together, these studies suggest that a $\mathrm{Fe}^{\mathrm{V}}(\mathrm{O})\left(\mathrm{O}_{2} \mathrm{CR}\right)$ intermediate is the oxidizing species when either peracetic acid or a combination of $\mathrm{H}_{2} \mathrm{O}_{2}$ and a carboxylic acid is employed. ${ }^{[4,6,10,11]}$ Recent computational studies have also suggested that a $\mathrm{Fe}^{\mathrm{V}}(\mathrm{O})\left(\mathrm{O}_{2} \mathrm{CR}\right)$ species may reversibly evolve in the formation of a cyclic percarboxylate moiety, $\mathrm{Fe}^{\mathrm{III}}\left(\mathrm{O}_{2} \mathrm{C}(\mathrm{O}) \mathrm{R}\right)$, thus alleviating the high reactivity associated with highly electrophilic $\mathrm{Fe}^{\mathrm{V}}$ centers. ${ }^{[12]}$

We have recently shown that the reaction of alkyl peracids with $\left[\mathrm{Fe}^{\mathrm{II}}\left(\mathrm{CF}_{3} \mathrm{SO}_{3}\right)_{2}\left(\mathrm{PyNMe}_{3}\right)\right]$ (1) in acetonitrile at low temperature $\left(-40^{\circ} \mathrm{C}\right)$ led to a transient species 2 that is kinetically competent for oxidizing strong $\mathrm{C}-\mathrm{H}$ bonds of alkanes (with bond dissociation energies of up to $100 \mathrm{kcal}$ $\mathrm{mol}^{-1}$ ) through an initial hydrogen atom transfer (HAT) mechanism. ${ }^{[13]}$ Compound $\mathbf{1}$ contains an iron center ligated, with a distorted octahedral geometry, to a strong-field 


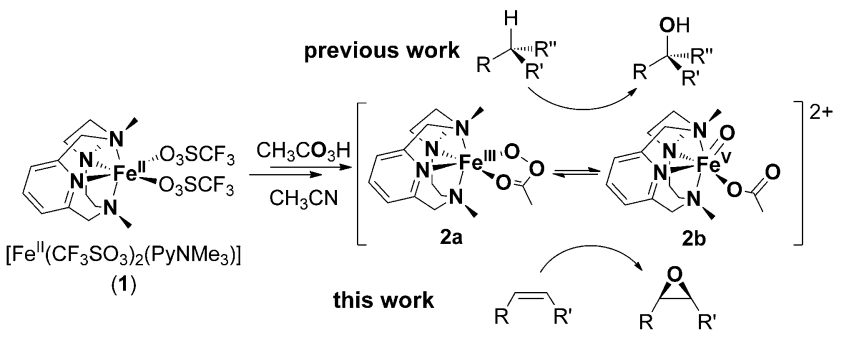

Scheme 2. Species $\mathbf{2}$ formed upon reaction of $\mathbf{1}$ with peracetic acid in acetonitrile.

tetradentate aminopyridine macrocyclic ligand, and also to two labile triflate anions that are cis to each other (Scheme 2). Therefore, $\mathbf{1}$ bears the chemical and structural properties associated with iron complexes that behave as powerful $\mathrm{C}-\mathrm{H}$ and $\mathrm{C}=\mathrm{C}$ oxidation catalysts. ${ }^{[3,14,15]} \mathrm{EPR}$ analyses have shown that 2 actually consists of two components, a major ([Fe ${ }^{\mathrm{V}}$ $\left.\left.(\mathrm{O})(\mathrm{OAc})\left(\mathrm{PyNMe}_{3}\right)\right]^{2+} ; 40 \%, \mathbf{2 b}\right)$ and a minor species $\left(\left[\mathrm{Fe}^{\mathrm{III}}-\right.\right.$ $\left.\left.(\mathrm{OOAc})\left(\mathrm{PyNMe}_{3}\right)\right]^{2+} ; 5 \%, 2 \mathbf{a}\right)$, in fast equilibrium, thus reproducing the reactivity that was predicted earlier for a related system on the basis of DFT calculations. ${ }^{[10]}$ Remarkably, the reaction of $\mathbf{2}$ towards alkanes occurred at unprecedentedly fast reaction rates compared to all previously spectroscopically characterized iron-based oxidants.

Motivated by the discovery of the extraordinary reactivity of $\mathbf{2}$ towards alkanes, we herein explored its ability to engage in oxygen atom transfer (OAT) reactions with olefins. By doing so, this work provides direct experimental evidence that a $\left[\mathrm{Fe}^{\mathrm{V}}(\mathrm{O})(\mathrm{OAc})\left(\mathrm{L}^{\mathrm{N} 4}\right)\right]^{2+}$ species is the OAT agent in catalytic epoxidation reactions with this class of catalysts, and establishes the role of steric and electronic factors in defining its reactivity.

The thermally unstable compound $\mathbf{2}$ was prepared by the reaction of $\mathbf{1}$ with 4 equiv peracetic acid at $-41^{\circ} \mathrm{C}$ in acetonitrile. This reaction was monitored by UV/Vis spectroscopy, showing the appearance of two absorption features in the visible region at 490 and $660 \mathrm{~nm}$ that are characteristic of 2. $^{[13]}$ Once maximized, the addition of cyclooctene (50 equiv) resulted in the immediate decay of the UV/Vis features associated with 2 . After the reaction, product analysis indicated that 1.3 equiv of the epoxide and 0.06 equiv of cis-2-acetoxycyclooctanol with respect to $\mathbf{2}$ had been formed.

The reaction of $\mathbf{2}$ towards olefinic substrates was very fast, and in order to determine the reaction rates, kinetic analyses required the performance of sequential stopped-flow experiments under cryogenic conditions at $-60^{\circ} \mathrm{C}$ using a $1: 3$ acetonitrile/acetone mixture as the solvent. The kinetics were monitored by following the decay of the $490 \mathrm{~nm}$ band, which is characteristic of $\mathbf{2}$, upon addition of excess olefin (Figure $1 \mathrm{a})$. The time traces were satisfactorily fitted to a single exponential to obtain the observed rate constants $\left(k_{\mathrm{obs}}\right)$, which showed a linear dependence on substrate concentration (Figure $1 \mathrm{~b}$; see also the Supporting Information, Figure S7), affording second-order rate constants $\left(k_{2}\right.$; Figure 2, top and Tables S1 and S2). Interestingly, the second-order reaction rates were independent of the peracid concentration $(2-$
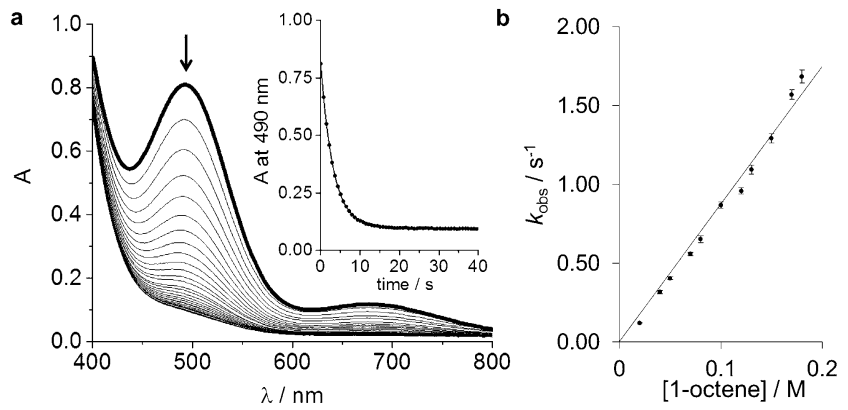

Figure 1. a) UV/Vis monitoring of the reaction of $\mathbf{2}$ with 1 -octene in acetonitrile/acetone $(1: 3)$ at $-60^{\circ} \mathrm{C}$. Inset: Decay of the $490 \mathrm{~nm}$ chromophore fitted to a single exponential. b) Plot of $k_{\text {obs }}$ against the 1-octene concentration for the reaction of 2 with 1 -octene at $-60^{\circ} \mathrm{C}$ in acetonitrile/acetone (1:3)

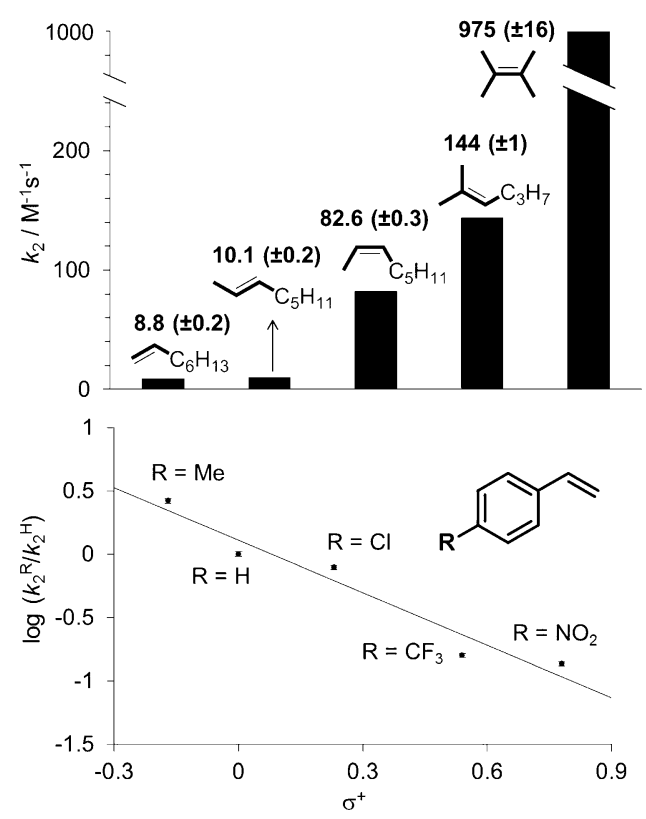

Figure 2. Top: Second-order rate constants $\left(k_{2}\right.$ in $\left.\mathrm{M}^{-1} \mathrm{~s}^{-1}\right)$ for the reaction of 2 towards selected alkenes at $-60^{\circ} \mathrm{C}$ in acetonitrile/ acetone $(1: 3)$. Bottom: Hammett plot for the reaction of 2 with a series of para-substituted styrenes at $-60^{\circ} \mathrm{C}$ in acetonitrile/acetone $(1: 3)$.

16 equiv with respect to $\mathbf{1}$ ) employed to form $\mathbf{2}$, indicating that neither the peracid nor the acetic acid that inevitably goes with it are responsible for the extraordinary reactivity of $\mathbf{2}$. Moreover, activation parameters were obtained for the reaction of $\mathbf{2}$ with 1-octene by performing experiments at different temperatures (Figure S8, Table S3). A small activation enthalpy $\left(\Delta H^{+}=28.4 \pm 0.5 \mathrm{~kJ} \mathrm{~mol}^{-1}\right)$ and a negative activation entropy $\left(\Delta S^{+}=-90 \pm 2 \mathrm{~J} \mathrm{~K}^{-1} \mathrm{~mol}^{-1}\right)$ were found, which are characteristic of a bimolecular process with a low enthalpic barrier. It is interesting to note that OAT from 2 towards sulfides was so fast that proper kinetic data could not be obtained with our stopped-flow equipment (see the Supporting Information).

The basic structural and electronic aspects that determine the relative reactivity of $\mathbf{2}$ towards olefins were also inter- 
rogated. The oxidation rate of $\mathbf{2}$ toward olefins $\left(k_{2}\right)$ increased as the degree of olefin substitution increased (Figure 2, top). Thus the rate for the oxidation of 2,3-dimethyl-2-butene with 2 was $975 \pm 16 \mathrm{M}^{-1} \mathrm{~s}^{-1}$, almost seven times higher than that for 2-methyl-2-hexene $\left(k_{2}=144 \pm 1 \mathrm{M}^{-1} \mathrm{~s}^{-1}\right)$, which in turn reacted around two and fourteen times faster than cis- and trans-2octene, respectively. The lowest rate was observed for 1-octene $\left(8.8 \pm 0.2 \mathrm{M}^{-1} \mathrm{~s}^{-1}\right)$. Most probably this is related to the increase in the electron density of the double bond, which is due to inductive effects of the substituents, ${ }^{[1]}$ which supports the hypothesis that $\mathbf{2}$ acts as an electrophile. Interestingly, these results indicate that electronic effects dominate over steric factors in determining the reactivity of $\mathbf{2}$ towards olefins. It is also particularly interesting that the relative reactivity was configuration-dependent and that the cis isomer was more prone to oxidation than the trans analogue, and reacted up to eight times faster in the case of 2-octene.

The impact of electronic effects in defining the relative reactivity of olefins with $\mathbf{2}$ was further studied in a systematic manner by analyzing the reaction rates for the reaction of $\mathbf{2}$ with several para-substituted styrenes. The logarithm of the second-order rate constants of the decay was plotted against the Hammett para substituent constants, $\sigma^{+}$, affording a good correlation $(R=0.95)$ and a negative slope $(\rho)$ of $-1.4 \pm 0.2$ (Figure 2, bottom; see also Table S4). The negative $\rho$ value confirms the electrophilic character of $\mathbf{2}$ in OAT reactions, ${ }^{[16,17]}$ which is in agreement with the increase in reactivity with increased olefin substitution (Figure 2, top).

Compound $\mathbf{1}$ acts as a catalyst in the epoxidation of olefins. The catalytic oxidation of excess 1-octene (100 equiv) at room temperature with peracetic acid (20 equiv) as the oxidant and $\mathbf{1}$ as the catalyst afforded 1-octene oxide as the major product $(12 \mathrm{TON}$; TON $=$ turnover number $)$ and the corresponding hydroxyacetate as the minor product (3 TON). Both compounds are proposed to be formed by the reaction of in situ generated 2 with the olefin. Comparison of the catalytic results obtained with the $\mathbf{1} / \mathrm{AcOOH}$ system $\left(1: 10: 100, \mathbf{1} / \mathrm{AcOOH} /\right.$ substrate, $\left.-60^{\circ} \mathrm{C}\right)$ with the kinetic data gathered for the reaction of $\mathbf{2}$ with alkenes demonstrates the relevance of $\mathbf{2}$ in catalytic epoxidation reactions. The selectivities of the $\mathbf{1} / \mathrm{AcOOH}$ catalytic reactions could be extracted from the competitive epoxidation of pairs of olefins $\left(\right.$ alkene $^{\mathrm{A}}$ and alkene $\left.\mathrm{B}^{\mathrm{B}}\right)$ in acetonitrile/acetone $(1: 3)$ at $-60^{\circ} \mathrm{C}$. Three different competition experiments were performed: styrene vs. 1-octene, cis-cyclooctene vs. cis-2-octene, and cisvs. trans-2-octene (Figure 3). Blank experiments showed that under these experimental conditions, uncatalyzed epoxidation is negligible ( $<3 \%$ with respect to the oxidant). Interestingly, the reactions occurred with stereoretention, and the relative amounts of the two epoxides formed after each competition reaction (epoxide ${ }^{\mathrm{A}} /$ epoxide $^{\mathrm{B}}$ ) reasonably matched the ratios of the corresponding $k_{2}$ values measured individually for the reaction of $\mathbf{2}$ with each olefin $\left(k_{2}{ }^{\mathrm{A}} / k_{2}{ }^{\mathrm{B}}\right)$. This remarkable agreement provides strong evidence that 2 constitutes the active species responsible for OAT in these catalytic epoxidations.

Aside from its selectivity, the fast reactivity of $\mathbf{2}$ is also consistent with a catalytically competent intermediate. The reaction rates of $\mathbf{2}$ towards alkenes are especially impressive
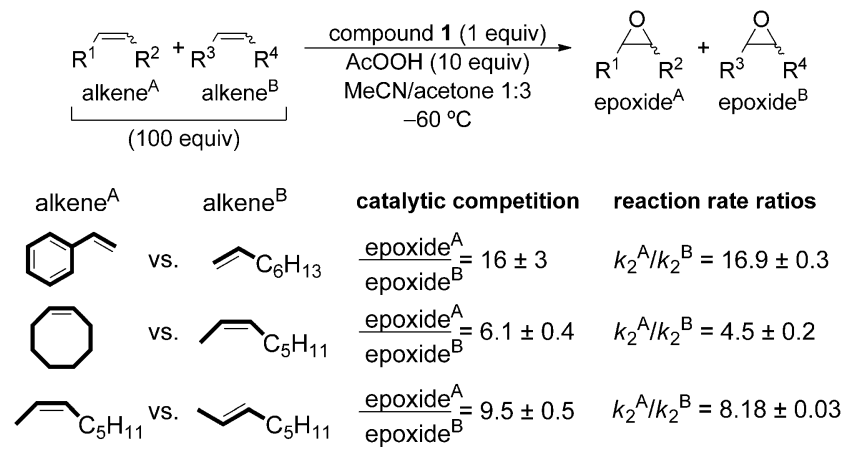

Figure 3. Intermolecular competitive epoxidation of pairs of olefins (alkene $^{A}$ and alkene ${ }^{B}$ ) by the $1 / \mathrm{AcOOH}$ catalytic system. Epoxide ${ }^{A} /$ epoxide $^{B}$ : ratio of the epoxide ${ }^{A}$ and epoxide ${ }^{B}$ products determined by $\mathrm{GC}$ analysis. $k_{2}{ }^{\mathrm{A}} / k_{2}{ }^{\mathrm{B}}$ : ratio of the second-order rate constants for the reaction of 2 with alkene $e^{A}\left(k_{2}^{A}\right)$ and alkene ${ }^{B}\left(k_{2}^{B}\right)$ in acetonitrile/acetone $(1: 3)$ at $-60^{\circ} \mathrm{C}$ determined by stopped-flow analysis.

when compared to other iron-oxygen species. It must be kept in mind that comparison with these compounds is not straightforward, as the oxidation state of the metal and the ligands, oxidants, and reaction conditions employed are not equivalent. Furthermore, a cautious note is warranted; ironcatalyzed epoxidations using other tetra- or pentadentate ligands have been studied, and alternative reaction mechanisms have been proposed. In most of these cases, the lack of accumulation of the OAT species, which is presumably very reactive, prevents comparison. ${ }^{[3,4,6,15,24]}$ With these limitations in mind, $\mathbf{2}$ can be ranked among the different types of ironoxygen species for which second-order reaction rates for OAT reactions have been determined (Table 1, Figure 4). The

Table 1: Second-order rate constants $\left(k_{2}\right)$ for the reaction of 2 and selected mononuclear iron-oxygen species with 1-octene, styrene, and cis-cyclooctene (see Figure 4 for the structures of compounds 3-9).

\begin{tabular}{lrllll}
\hline Catalyst & $T\left[{ }^{\circ} \mathrm{C}\right]$ & \multicolumn{4}{c}{$k_{2}\left[\mathrm{M}^{-1} \mathrm{~s}^{-1}\right]$} \\
1-octene & styrene & Ref. \\
\hline $\mathbf{2}$ & -60 & $8.8 \pm 0.2$ & $149 \pm 3$ & $375 \pm 15$ & this work \\
$\mathbf{3}$ & 0 & - & - & 0.45 & {$[18]$} \\
$\mathbf{4}$ & 20 & - & - & 0.032 & {$[19]$} \\
$\mathbf{5}$ & 25 & - & 0.026 & - & {$[20]$} \\
$6^{[\mathrm{a}]}$ & 25 & - & $0.043 \pm 0.003$ & - & {$[21]$} \\
$\mathbf{7}$ & -40 & 5.3 & - & 3.3 & {$[22]$} \\
$\mathbf{8}$ & $\mathrm{RT}$ & - & $148 \pm 8.1$ & $29 \pm 3.6$ & {$[17]$} \\
$\mathbf{9}$ & -60 & - & 0.4 & - & {$[23]$} \\
\hline
\end{tabular}

[a] Proton-coupled electron transfer (PCET) in the presence of HOTf. Compound 6 itself cannot oxidize styrene.

iron(IV) oxo complexes $\mathbf{3}^{[18]}$ and $\mathbf{4}^{[19]}$ bearing pyridinecontaining macrocyclic ligands, and $\mathbf{5}$ with a $\mathrm{N}_{2} \mathrm{~S}_{2}$ thioether ligand ${ }^{[20]}$ exhibit rates that are three to four orders of magnitude lower than $\mathbf{2}$, but these reactions were carried out at much higher temperatures. The same difference in reactivity was observed for the iron(IV) oxo complex $\mathbf{6}$, which bears a pentadentate N4Py ligand, in the presence of triflic acid. ${ }^{[21]}$ Compound 2 also shows higher reaction rates than the more reactive $S=2$ iron(IV) oxo complex 7, which was 


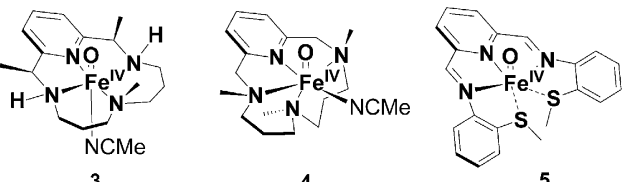

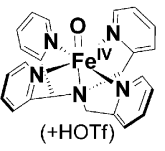

6

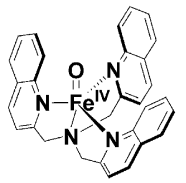

7

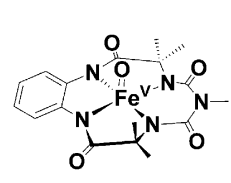

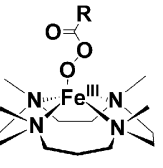

Figure 4. Spectroscopically detected nonheme iron-oxygen species for which alkene epoxidation rates have been determined.

recently reported by Que and co-workers, and shows an oxidation rate for 1-octene $\left(5.4 \mathrm{M}^{-1} \mathrm{~s}^{-1}\right.$ at $\left.-40^{\circ} \mathrm{C}\right)$ that is of the same order of magnitude as that for $2\left(8.8 \mathrm{M}^{-1} \mathrm{~s}^{-1}\right.$ at $\left.-60^{\circ} \mathrm{C}\right)$. However, the rate of cis-cyclooctene oxidation by $\mathbf{3}$ is two orders of magnitude lower than for $2 .{ }^{[22]}$ The rate obtained for cis-cyclooctene oxidation by the TAML oxo iron(V) species 8 $\left(29 \mathrm{M}^{-1} \mathrm{~s}^{-1} \text { at } 25^{\circ} \mathrm{C}\right)^{[17]}$ is still ten times lower than that for $\mathbf{2}$ at $-60^{\circ} \mathrm{C}\left(375 \mathrm{M}^{-1} \mathrm{~s}^{-1}\right.$ at $\left.-60^{\circ} \mathrm{C}\right)$ without correcting for the $80^{\circ} \mathrm{C}$ difference, meaning that $\mathbf{2}$ reacts much faster than 8 . Interestingly, the recently reported high-spin iron(III) acylperoxo complex 9 oxidizes styrene almost 400 times slower than $2^{[23]}$ This reactivity difference is especially striking because it further highlights that the cleavage of the $\mathrm{O}^{-} \mathrm{O}$ bond is crucial for creating a uniquely powerful oxidation agent. Other iron(III) acylperoxo species have been reported but they proved to be either sluggish oxidants in OAT, ${ }^{[25]}$ kinetically incompetent to perform this chemistry ${ }^{[10]}$ or no reactivity studies have been undertaken. ${ }^{[26-28]}$ The latter include Fe complexes based on pyridinophane ligands structurally related to $\mathrm{PyNMe}_{3}$, for which no direct evaluation of the reactivity of the spectroscopically trapped iron-oxygen species was reported, and no direct comparison can be established with the current system. ${ }^{[28,29]}$ Finally, the superior reactivity of $\mathbf{2}$ is also illustrated by its faster reaction ( 2 or 3 orders of magnitude) when compared to synthetic iron(IV) oxo porphyrin radical species, which reproduce the electronic structure of compound I of cytochrome P450 and related enzymes (see the Supporting Information). ${ }^{[30,31]}$

Overall, compound $\mathbf{2}$ stands out amongst all previously reported iron-oxygen species for olefin oxidation. Furthermore, our observations provide experimental support for the proposal that the acetic acid effect in iron-catalyzed epoxidations is (at least partially) due to facilitating the $\mathrm{O}-\mathrm{O}$ heterolytic cleavage to form a highly reactive iron(V) oxo acetato complex such as $\mathbf{2} \cdot{ }^{[32]}$

In conclusion, $\mathbf{2}$ is an exceedingly reactive compound with second-order reaction rate constants that, to the best of our knowledge, render this molecule the fastest OAT agent described to date. Most significantly, the agreement between the reaction rates determined by stopped-flow analysis and the selectivity properties of $\mathbf{2}$ under catalytic epoxidation conditions provide solid evidence that it is a truly competent intermediate and a plausible OAT agent with broad relevance in biologically inspired nonheme iron oxidation catalysis.

\section{Acknowledgements}

Financial support for this work was provided by the European Commission (2011-CIG-303522 to A.C. and ERC-2009-StG239910 to M.C.), the Spanish Ministry of Science (CTQ201237420-C02-01/BQU to M.C., CTQ2012-37821-C02-02 to M.G.B., CTQ2013-43012-P to A.C., CTQ2013-48917-C3-1-P to R.B. and E.G.-E.), the Unidad de Excelencia (MDM 20150038 and CSD2010-00065 to M.C., M.G.B., R.B., and E.G.-E), the Generalitat Valenciana (PROMETEOII 2015/002t to R.B. and E.G.-E.), and the Generalitat de Catalunya (ICREA Academia Award to M.C. and 2014SGR-862). The Spanish Ministry of Science is also acknowledged for a Ramón y Cajal contract to A.C. (RYC-2011-08683). Prof. Lawrence Que, Jr. from the University of Minnesota is acknowledged for fruitful discussions.

Keywords: epoxidation - kinetics - nonheme iron complexes . olefins $\cdot$ oxidation

How to cite: Angew. Chem. Int. Ed. 2016, 55, 6310-6314 Angew. Chem. 2016, 128, 6418-6422

[1] E. A. Mikhalyova, O. V. Makhlynets, T. D. Palluccio, A. S. Filatov, E. V. Rybak-Akimova, Chem. Commun. 2012, 48, $687-689$.

[2] S. Huber, M. Cokoja, F. E. Kühn, J. Organomet. Chem. 2014, 751, $25-32$.

[3] K. P. Bryliakov, E. P. Talsi, Coord. Chem. Rev. 2014, 276, 73 - 96.

[4] O. Cussó, I. Garcia-Bosch, X. Ribas, J. Lloret-Fillol, M. Costas, J. Am. Chem. Soc. 2013, 135, $14871-14878$.

[5] Y. Nishikawa, H. Yamamoto, J. Am. Chem. Soc. 2011, 133, 8432 8435 .

[6] R. Mas-Ballesté, L. Que, Jr., J. Am. Chem. Soc. 2007, 129, $15964-15972$.

[7] M. C. White, A. G. Doyle, E. N. Jacobsen, J. Am. Chem. Soc. 2001, 123, 7194-7195.

[8] G. Dubois, A. Murphy, T. D. P. Stack, Org. Lett. 2003, 5, 2469 2472.

[9] C. Marchi-Delapierre, A. Jorge-Robin, A. Thibon, S. Menage, Chem. Commun. 2007, 1166-1168.

[10] W. N. Oloo, K. K. Meier, Y. Wang, S. Shaik, E. Münck, L. Que, Jr., Nat. Commun. 2014, 5, 3046.

[11] O. Y. Lyakin, A. M. Zima, D. G. Samsonenko, K. P. Bryliakov, E. P. Talsi, ACS Catal. 2015, 5, 2702-2707.

[12] Y. Wang, D. Janardanan, D. Usharani, K. Han, L. Que, Jr., S. Shaik, ACS Catal. 2013, 3, 1334-1341.

[13] J. Serrano-Plana, W. N. Oloo, L. Acosta-Rueda, K. K. Meier, B. Verdejo, E. García-España, M. G. Basallote, E. Münck, L. Que, Jr., A. Company, M. Costas, J. Am. Chem. Soc. 2015, 137, $15833-15842$.

[14] O. Cussó, X. Ribas, M. Costas, Chem. Commun. 2015, 51, 14285 14298.

[15] W. N. Oloo, L. Que, Jr., Acc. Chem. Res. 2015, 48, 2612-2621.

[16] C. V. Sastri, M. S. Seo, M. J. Park, K. M. Kim, W. Nam, Chem. Commun. 2005, 1405-1407.

[17] K. K. Singh, M. k. Tiwari, B. B. Dhar, K. Vanka, S. Sen Gupta, Inorg. Chem. 2015, 54, 6112-6121.

[18] W. Ye, D. M. Ho, S. Friedle, T. D. Palluccio, E. V. RybakAkimova, Inorg. Chem. 2012, 51, 5006-5021.

[19] W. Ye, R. J. Staples, E. V. Rybak-Akimova, J. Inorg. Biochem. 2012, $115,1-12$. 
[20] J. Annaraj, S. Kim, M. S. Seo, Y.-M. Lee, Y. Kim, S.-J. Kim, Y. S. Choi, H. G. Jang, W. Nam, Inorg. Chim. Acta 2009, 362, 1031 1034.

[21] J. Park, Y.-M. Lee, K. Ohkubo, W. Nam, S. Fukuzumi, Inorg. Chem. 2015, 54, 5806-5812.

[22] A. N. Biswas, M. Puri, K. K. Meier, W. N. Oloo, G. T. Rohde, E. L. Bominaar, E. Münck, L. Que, Jr., J. Am. Chem. Soc. 2015 137, 2428-2431.

[23] B. Wang, Y.-M. Lee, M. Clémancey, M. S. Seo, R. Sarangi, J.-M. Latour, W. Nam, J. Am. Chem. Soc. 2016, 138, 2426-2436.

[24] J. Bautz, P. Comba, C. Lopez de Laorden, M. Menzel, G. Rajaraman, Angew. Chem. Int. Ed. 2007, 46, 8067-8070 Angew. Chem. 2007, 119, 8213-8216.

[25] X. Zhang, H. Furutachi, T. Tojo, T. Tsugawa, S. Fujinami, T. Sakurai, M. Suzuki, Chem. Lett. 2011, 40, 515-517.

[26] O. V. Makhlynets, W. N. Oloo, Y. S. Moroz, I. G. Belaya, T. D. Palluccio, A. S. Filatov, P. Müller, M. A. Cranswick, L. Que, Jr., E. V. Rybak-Akimova, Chem. Commun. 2014, 50, 645-648.
[27] G. Guisado-Barrios, Y. Zhang, A. M. Harkins, D. T. Richens, Inorg. Chem. Commun. 2012, 20, 81-85.

[28] J. R. Khusnutdinova, J. Luo, N. P. Rath, L. M. Mirica, Inorg. Chem. 2013, 52, 3920-3932.

[29] T. W.-S. Chow, E. L.-M. Wong, Z. Guo, Y. Liu, J.-S. Huang, C.-M. Che, J. Am. Chem. Soc. 2010, 132, 13229-13239.

[30] L. Ji, A. Franke, M. Brindell, M. Oszajca, A. Zahl, R. van Eldik, Chem. Eur. J. 2014, 20, 14437-14450.

[31] N. Hessenauer-Ilicheva, A. Franke, D. Meyer, W.-D. Woggon, R. van Eldik, J. Am. Chem. Soc. 2007, 129, 12473-12479.

[32] A reviewer suggested that the acetic acid may be the reason for the high reaction rates observed for $\mathbf{2}$. However, we note that the second-order rate constants are independent of the amount of peracid employed for its generation.

Received: February 8, 2016

Revised: March 21, 2016

Published online: April 13, 2016 